\title{
A LEITURA INTERDISCIPLINAR DO REISADO DO CIPÓ DE BAIXO (PEDRO II - PI)
}

\section{THE INTERDISCIPLINARY READING OF THE CIPÓ DE BAIXO (PEDRO II - PI)}

\author{
Luciano de Melo Sousa ${ }^{1}$
}

\begin{abstract}
RESUMO
Esta pesquisa estuda a tradição do reisado da comunidade Cipó de Baixo, do município piauiense de Pedro II. A leitura feita procura ressaltar a processualidade da brincadeira que navega entre a permanência e a transformação. $\mathrm{O}$ artigo destaca o processo de construção da pesquisa por meio da descrição de seu referencial teórico-metodológico. Este é composto por contribuições da Antropologia, Sociologia e História Cultural. Com base nele descreve como foi feita a pesquisa de campo por meio de um enfoque interdisciplinar.
\end{abstract}

Palavras-chave: Reisado. Dinamismo cultural. Interdisciplinaridade.

\begin{abstract}
This research studies the epiphany tradition in the community of Cipó de Baixo, which belongs to the city of Pedro II in the state of Piauí. The readings and interpretations sought to highlight the process involved in the play that goes from permanence to change. The article highlights the process of building the research through the description of its theoretical and methodological framework. This consists of contributions from Anthropology, Sociology and Cultural History. Based on this framework the article describes how the field research was carried out through an interdisciplinary approach.
\end{abstract}

Keywords: Epiphany. Cultural dynamism. Interdisciplinarity.

\section{Introdução}

A pesquisa, da qual este artigo se origina, é um estudo de caso sobre a tradição do reisado da comunidade rural Cipó de Baixo, no município de Pedro II. A leitura que fazemos dessa tradição vai além de uma visão linear e pontual da brincadeira e de seus elementos constitutivos. Situamos a brin- cadeira do Cipó no campo do dinamismo cultural, no qual avaliamos suas permanências e transformações. Para tanto, por meio de observação de campo e de entrevistas com os brincantes e apaixonados pelo "movimento", contextualizamos os atores e o mundo social no qual estão inseridos bem como suas continuidades e mudanças. Por meio dessa compreensão geral, percorremos a trama de cipós que vêm

${ }^{1}$ Doutor em Ciências Sociais pela Universidade Federal do Rio Grande do Norte. Professor adjunto da Universidade Estadual do Piauí. E-mail: lucianomelo.s@ bol.com.br 
constituindo $^{2}$ a brincadeira do Cipó de Baixo, seus atores e suas comunidades. Nesse sentido, tanto tomamos o universo social para compreender o que vem sendo a prática cultural do reisado, como também consideramos a totalidade da brincadeira para entender como vêm se comportando as pessoas da comunidade Cipó e comunidades circunvizinhas tradição do reisado do Cipó e mundo social do qual faz parte são colocados como partes de uma totalidade em que há mútuas contaminações. Por essas razões, nosso estudo situa-se no campo interdisciplinar da Antropologia, Sociologia e História Cultural.

Como grande cenário desse cipoal de relações sociais, situamos a modernidade capitalista. Ela ordena determinados parâmetros gerais que orientam novos padrões de sociabilidade nas localidades rurais de Pedro II, com características ainda tradicionais. Nesse movimento contraditório, os agrupamentos sociais navegam entre novidades e tradições. Esse mar social estável-instável também põe em movimento a tradição do reisado do Cipó. Nossa pesquisa persegue essa cipoada de relações sociais, movimentos e permanências. Como uma espécie de carta náutica, procuramos descrever as formas, cores, texturas e espessuras desse emaranhado de cipós sociais para navegarmos com mais conforto no mar sempre surpreendente e fascinante da cultura. À medida que lemos o reisado do Cipó somos instigados a pensar por meio de novas referências o oceano aparentemente pacífico das práticas culturais: certamente que essa foi a grande empreitada reflexiva da pesquisa.

Nesse sentido, o desenho de nossa investigação configurou-se como prática interdisciplinar de pesquisa. "Brincadeira do reisado na comunidade Cipó, Pedro II - PI: mediação cultural, tradição e modernidade" é um estudo no qual são apropriados referenciais de História Cultural, Antropologia e Sociologia como constituintes de um quadro teórico, independentemente de suas fronteiras disciplinares. O conhecimento nas ciências humanas é um exercício reflexivo livre capaz de lançar luzes de interpretação sobre os fatos, independentemente dos nichos de conhecimento. Memória, cultura, identidade, tradição e modernidade não são categorias exclusivas de determinadas disciplinas: fazem parte do cabedal

\footnotetext{
${ }^{2} \mathrm{O}$ emprego do gerúndio é um recurso linguístico para ressaltar o esforço de leitura processual que fazemos do reisado.
}

teórico das ciências humanas. Nosso esforço foi de, mediante as possibilidades heurísticas daqueles referenciais teóricos, construir uma interpretação sobre o reisado da comunidade rural Cipó.

Este artigo procura dar conta desse suporte teórico-metodológico que orientou a nossa proposta investigativa. Desejamos esclarecer como surgiu a pesquisa, com que referências teóricas dialoga e, associado a esse referencial teórico, o percurso metodológico feito. A proposta é apresentar uma visão detalhada de como investigamos o reisado da comunidade Cipó ${ }^{3}$ com fundamento em determinada experimentação interdisciplinar. Por essa razão, descrevemos o processo de coleta de dados ao tempo que explicamos as razões das escolhas metodológicas feitas. A intenção é apresentar ao leitor uma discussão detalhada de como construímos a pesquisa de campo a partir da problematização do reisado no universo do dinamismo cultural.

Nesse exercício analítico acerca de metodologia de pesquisa, tomamos emprestadas referências da Sociologia, Antropologia e História. Nessas ciências encontramos amparo para apreender o processo vivido pelos brincantes do reisado e as próprias comunidades do Cipó e circunvizinhas. Entender o cotidiano dessas pessoas e comunidades e apreender os processos de mudança cultural são as metas do aporte metodológico descrito neste artigo. Uma pesquisa que lida com memórias, representações, práticas e tradições culturais e a reinvenção da vida cultural.

Assim, o artigo divide-se em quatro partes: "as origens da pesquisa" (situa o processo de elaboração da pesquisa que fez parte de nosso doutoramento), "nosso objeto de estudo: tradição e dinamismo cultural na modernidade" (esclarece sucintamente o problema da pesquisa), "a trajetória teórico-metodológica" (explica detalhadamente as escolhas metodológicas que orientaram a apreensão da realidade do reisado) e "palavras finais" (discute o sentido da interdisciplinaridade nesta pesquisa).

\footnotetext{
${ }^{3}$ A comunidade do Cipó de Baixo situa-se no município de Pedro II, norte do Piauí, na região dos Cocais. Dista a duzentos quilômetros da capital Teresina. Sua população compreende 37.500 (trinta e sete mil e quinhentos habitantes), conforme censo do IBGE de 2010. A comunidade localiza-se, aproximadamente, a dezoito quilômetros da sede. Com uma população aproximada de 160 pessoas, na sua grande maioria composta de agricultores, nela se encontra o reisado de seu Raimundo Milú.
} 


\section{As origens da pesquisa}

A ideia de pesquisa nasceu, como toda boa ideia, eivada de contradições e prenhe de intenções humanistas. Propomos elaborar uma "teoria sociológica da cultura piauiense" sioso, era um projeto equivocado. Pretensioso, pois não caberia no escopo de uma pesquisa, mesmo que uma pesquisa de doutorado. E equivocado? Primeiramente, as leituras e reflexões feitas para cá desconstruíram a hipótese de uma "cultura piauiense". $\mathrm{O}$ argumento de um sistema estruturado e unitário - a cultura piauiense - é insustentável dado o caráter múltiplo, contraditório e aberto de toda sociedade moderna.

Outra insustentabilidade do projeto inicial residia na defesa de um essencialismo cultural. Segundo ele, há certos elementos culturais recorrentes que garantiriam o caráter de "piauiensidade". Sob a influência de teóricos que advogam uma cultura nacional brasileira, propunha estudar um ethos piauiense (WEBER, 2002) em meio a uma diversidade de práticas culturais, processos históricos diferenciados de formação do estado do Piauí, desigualdades de desenvolvimento econômico e distinções políticas várias na história passada e presente do Piauí. A diversidade de nossa formação histórica, a multiplicidade de costumes e crenças, as trocas culturais permanentes com o mundo, a ausência de uma política cultural de estado no Piauí, diferenças e desigualdades econômicas, políticas e sociais do Piauí levaram a desfazer aquele tratamento essencialista do universo cultural.

Outro questionamento feito sobre o projeto inicial consistiu na dúvida sobre "cultura". O sentido consagrado de cultura como uma totalidade sistemática, una, integradora e territorialmente definida vem sendo colocado em xeque pelos estudos contemporâneos sobre identidade cultural, globalização e pós-modernidade (HALL, 2006; ORTIZ, 2005; BAUMAN, 1998; GILROY, 2001). A cultura não pode mais ser tratada como uma totalidade sólida, indivisa, integradora, espacial e temporalmente delimitada. As construções culturais vêm sendo tratadas como práticas históricas, contraditórias, intercambiáveis, dinâmicas, híbridas e desterritorializadas. As-

${ }^{4}$ Extraído do projeto apresentado ao programa de Pós-Graduação em Ciências Sociais da UFRN como parte do processo de seleção de 2008. sim sendo, como propor o estudo d $a$ cultura piauiense?

Foi assim que abandonamos a ideia original e transformamos essa mesma caminhada de desconstrução em elementos problematizadores da pesquisa: o que significa existir socialmente pelo viés das práticas culturais? Como compreender o dinamismo cultural em sociedades inclinadas ontologicamente a mudanças (sociedades capitalistas)? Que luzes um estudo de caso sobre uma prática cultural em mudança - a brincadeira do reisado na comunidade Cipó de Baixo, no município de Pedro II, estado do Piauí - pode lançar sobre as dinâmicas culturais da modernidade? Como uma antiga tradição (brincadeira do reisado) serve como mecanismo de resistência/ diálogo cultural? ${ }^{5}$

Essa memória da pesquisa é importante à medida que esclarece os itinerários trilhados nessa caminhada cognitiva. Se, por um lado, explica os percursos de imaginações teóricas feitos, por outro lado, acentua o caráter manufatureiro/pessoal do conhecimento. Essa manufatura que se vem urdindo dia a dia com fios de matizes diversos, numa trama singular de pessoalidade, leituras particulares, trocas existenciais com a gente do Cipó associada à prática cotidiana de construção/desconstrução de conceitos, ideias, sonhos e expectativas. A ciência é uma criação artesanal e eivada por muita pessoalidade.

\section{Nosso objeto de estudo: tradição e dinamismo cultural na modernidade}

Nosso trabalho é um estudo de caso que avalia como se comportam uma tradição cultural e seus atores sociais pertencentes a comunidades rurais do município piauiense de Pedro II. À medida que estuda esse complexo de ações e significados sociais, situa-o dentro de um quadro de categorias e teorias das ciências humanas e, nesse exercício cognitivo, constrói algumas pistas explicativas sobre a dinâmica cultural criada em torno da tradição do reisado e, seguindo a mesma trilha, levanta alguns questionamentos teóricos em torno das categorias com as quais dialoga.

\footnotetext{
${ }^{5}$ Como bem recorda Ugo Maia Andrade, "todos nós sabemos que as perguntas que guiaram uma pesquisa em seus primeiros passos não são exatamente as mesmas nos estágios subsequentes" (2008, p. 47).
} 
Escrevemos sobre os significados das coisas para os indivíduos que vivem em comunidades tradicionais em processo de transformação modernizadora. Paulatinamente, práticas, produtos e conceitos da modernidade invadem as comunidades rurais, pondo em crise seus antigos sistemas de referência tradicional. Nada mais é tão certo e tranquilo como em tempos pretéritos. A brincadeira do reisado acontece agora em comunidades abertas e não mais conservadoras. Os sistemas de significados que seus moradores compartilham são múltiplos e, ao mesmo tempo, tensos e dinâmicos. Tanto o é que o reisado já não é o mesmo, bem como os significados que o fazem existir são plurais e contraditórios.

Existir de modo particular pela afirmação de certos conceitos, valores, atitudes e trocas sociais tem que possuir significados para quem vive a brincadeira? E para o exterior? O que significa participar do mundo, a partir de um cosmo particular de sentidos e ações sociais? $O$ fato de a brincadeira do reisado resistir na comunidade Cipó demonstra que os localismos mantêm-se vivos (apesar de suas contradições internas). Escrever sobre os brincantes do reisado é escrever sobre os vastos modos de existir socialmente. Esses vastos modos de existir são construtos identitários tensos e em constante movimento.

A modernidade sobrecarregou as sociedades com um sentido de unidade - $o$ capitalismo, $a$ democracia, $o$ Estado, $a$ educação nacional, $a$ cultura capitalista, $a$ arte moderna, $a$ língua nacional etc. Particularmente, no campo das culturas, o domínio da unidade hegemônica procurou domesticar as diferenças culturais sob as alcunhas de "cultura popular", "folclore", "cultura do povo". Ao catalogar as diferenças culturais - localização, personagens, indumentárias, modos de ser e agir, periodicidades etc. - a política do Estado unitário e hegemônico procurou disciplinar o universo das culturas. Essa disciplina das "outras" culturas transformou a cultura que reproduz os valores hegemônicos da modernidade na cultura legítima, na cultura nacional. As "outras" culturas disciplinadas existem tão somente para escolas, meios de comunicação, órgãos estatais, igrejas, cidadãos comuns, indústria cultural por meio das representações da cultura dominante.

Os brincantes de reisado do Cipó, como tantas outras experiências de identidade cultural, exercitam uma espécie de liberdade cultural. Liberdade essa que não se confunde com "pureza" ou "isolamento cultural". Em meio às trocas culturais acentuadas da globalização, os protagonistas daquelas experiências de identidade cultural fazem escolhas. Eles se autodenominam, definem suas prioridades, escolhem como e onde vão brincar, negociam patrocínios etc.

$\mathrm{O}$ que mais se destaca entre os participantes da brincadeira do reisado é certa margem de movimentação que os fazem navegar entre resistências e mudanças, entre memórias e novas histórias, entre a vida e a morte, entre o certo e o incerto. Não há conceitos prontos ou importados; os sentidos apresentados por eles nascem de suas experiências e também dos conflitos entre seus protagonistas e tensões com o mundo externo.

Em tempos de economias desterritorializadas, de "poderes "desterritorializados" (BECK, 2003, p. 44), de culturas desterritorializadas (GILROY, 2001), de "diálogos interculturais de direitos humanos" (SANTOS, 2000, p. 28), o que pensar sobre a existência cultural? O que significa viver no mundo experimentando certas referências culturais num universo de infinitas configurações culturais? O que dizer sobre pessoas que, ao tempo que estão vivendo práticas culturais hegemônicas da sociedade capitalista, interagem também num campo de sociabilidade particular? O que representa esse "diálogo cultural" entre quadros simbólicos da hegemonia moderna e outros sistemas de autorreferência cultural? O que há de transgressor nessa postura? O que há de sujeição social? Esse diálogo cultural deve ser avaliado pela ótica da polarização alienação-recusa? Ou exige de sociólogos, historiadores e antropólogos novos critérios de análise? “(...) a ideia de que a globalização significa o desarraigamento absoluto, a mistura absoluta das culturas, o adeus à memória da localidade, enfim, todos esses quadros espantosos são no mínimo unilaterais" (BECK, 2003, p. 52)

Por essa razão, nosso trabalho também põe em movimento o conceito de "cultura". O fato cultural não existe mais como unidade espacial e temporal. Especular acerca da "unidade", "natureza" ou "essência" de certa cultura é negar o fato de que o mundo vive sob a pressão das trocas, das redes, das relações. É nesse mundo novo que se faz urgente rever as teorias sobre cultura: concomitante às particularidades de um grupo, comunidade ou nação, há uma explosão de práticas culturais globais. Os agrupamentos humanos se põem em comunicação com o mundo por uma necessidade de sobrevivência: não é mais 
possível manter-se alheio ao resto do mundo e aos processos permanentes de mediação cultural, pois “(...) convivências tão intensas e frequentes como as que nosso mundo exige serão incompreensíveis se compartimentarmos as sociedades, como fez o relativismo cultural que imaginava cada cultura isolada e autossuficiente." (CANCLINI, 2007, p. 32)

Categorias como "relativismo cultural", "aculturação", "cultura nacional", "cultura popular" carecem de uma reinvenção vistos os movimentos do mundo e dos saberes. Alguns estudiosos têm enfrentado esse desafio de construir trajetórias novas de contemplação conceitual dos universos culturais. Entre esses percursos novos, destaco a crítica à acepção de cultura. "Não existe uma fronteira cultural nítida ou firme entre grupos, e sim, pelo contrário, um continuum cultural" (BURKE, 2006, p. 14).

A antropóloga brasileira Antonella Tassinari, em sua etnogênese das famílias Karipuna, no estado do Amapá, entre outros questionamentos, pontua as críticas feitas à cultura como um padrão unitário e totalizante. Vários estudos já apontam para a “(...) importância de redefinir o conceito em termos mais dinâmicos" (2003, p. 34). Os estudos hermenêuticos sobre cultura têm trazido novas questões:
À ideia de cultura como unidade, como código comum ou padrões de relacionamentos com- partilhados por todos os membros de determinada comunidade, contrapõem-se as abordagens que veem a cultura a partir da pluralidade de inter- pretações ou de posições dos vários sujeitos, os quais também não fazem mais parte de uma comunidade com limites fechados e claramente definidos. A cultura não aparece mais como definidora do pertencimento dos indivíduos a grupos étnicos. Finalmente, também entram em cena emoções e vontades dos sujeitos, como elementos importantes para a construção do novo conceito de "cultura".

Nessa genealogia da crítica ao conceito de cultura, Tassinari retoma pesquisadores como Geertz, Sahlins, Barth, entre outros, para fundamentar sua proposição.

\section{A trajetória teórico-metodológica}

Nosso trabalho situa-se no complexo e sempre aberto universo da pesquisa qualitativa, pois nosso material de estudo é composto por complexos de significados sociais. Procuramos entender as relações de sentido (FLICK, 2009) criadas em torno da brincadeira do reisado da comunidade rural Cipó de Baixo, no município de Pedro II. Ao lançar-se sobre esse campo aberto de significações e representações, destacamos os sentidos que orientam as movimentações, escolhas e relações mantidas em torno dessa tradicional brincadeira que passa nos últimos anos por fortes e significativas transformações.

Os brincantes do reisado são atores sociais determinados por um tempo e um espaço social. O espaço é aquele definido pelas relações de parentesco, compadrio e amizades que extrapolam a comunidade Cipó de Baixo. O tempo é uma construção tensa que se estende entre as práticas tradicionais e a modernidade. Esses brincantes, condicionados por um tempo e um espaço social determinados, constroem relações, erigem costumes, instituem significados, fundam compromissos sociais, enfim, navegam por um campo de sociabilidades muito próprias que constitui um padrão singular de vivência social do reisado - o reisado do Cipó. Vivência essa marcada por uma oposição fundamental: permanência-transformação. Esse campo de sentidos, ações e tensões é o campo de sociabilidades que tomamos para compreender a brincadeira do reisado do Cipó. Tendo como base essa problemática que estruturamos nosso sinuoso processo de apreensão do objeto.

À medida que esclarecemos as escolhas e os caminhos trilhados para nossa apropriação do reisado, demonstramos que os percursos de investigação foram múltiplos e complexos. Combinamos técnicas de pesquisa das ciências humanas com algumas posturas e juízos sobre a apropriação do problema estudado. Apesar da pequena experiência em investigações, construímos algumas balizas que foram contribuindo com a sinuosa jornada de discussão daquele pequeno universo social sintetizado na materialidade do reisado da comunidade Cipó de Baixo. Esse tópico lança luz sobre as trilhas percorridas nas quais urdimos os cipós do reisado.

[...] toda organização societal está assentada nos "sentidos", nas "definições" e nas "ações" que indivíduos e grupos elaboram ao longo do processo de "interação simbólica" do dia a dia. A sociedade quase que se confunde com a interação simbólica que representa seu próprio substrato. (HAGUETTE, 2010, p. 62 e 63). 
A pesquisadora cearense, ao procurar justificar a técnica da observação participante, destaca que toda vida em sociedade se realiza mediante vasta representação simbólica. Somos sujeitos de sentidos: carecemos de produção simbólica para existirmos como seres sociais. Em todas as experiências da vida social, produzimos e reproduzimos ideias, representações, significados, convenções. Já há vasta elaboração teórica para justificar essa premissa básica do conhecimento das Ciências Sociais (DURKHEIM, 1989; GEERTZ, 1989; BOURDIEU, 1987; BERGER; LUCKMANN, 1985).

O que nos interessa no momento é reforçar essa argumentação de Haguette em favor da observação participante. Para compreender a brincadeira do reisado, foi necessário mergulhar no vasto e complexo sistema de significados dos brincantes, das famílias que recebem o reisado e de suas comunidades. Para visualizar e compreender essas redes de significação, precisamos estar presente, por algum tempo, no cotidiano das vidas dos brincantes. Observar, perguntar, colaborar com alguma atividade, enfim, estar presente no dia a dia da família de seu Raimundo Milú e dos brincantes mais próximos. Ao estabelecer relações mais estreitas, fomos, pouco a pouco, tecendo liames de compreensão entre os elementos observados e as entrevistas realizadas.

Além da observação participante, verificamos ser necessária à construção do enredo interpretativo a realização de entrevistas não estruturadas: o seu registro fora feito ora em áudio, ora em vídeo. Elas serviram para apreendermos elementos que fugiam ao olhar do observador bem como contribuir com a construção de relações de significado entre eles. Ao tempo que usufruíamos das entrevistas, percebemos que lidar tão somente com elas limitaria a profundidade da exegese de nosso objeto. Como bem avalia Haguette (2010, p. 82), a entrevista está muito centrada na figura do pesquisador: é ele que elabora o roteiro de entrevista, a partir de sua interpretação da realidade além de aparecer como uma figura estranha ao universo do entrevistado. Mesmo reconhecendo que a "autoria" da interpretação é de competência do pesquisador, desde sempre desejávamos perceber aquele mundo por palavras, gestos, pensamentos, atitudes e relações de seus atores sem a autoridade excessiva do olhar do investigador. Relativizar foi uma orientação sempre atuante: para tanto, busca- mos desconfiar e/ou desconstruir as nossas primeiras inferências. Quantos solilóquios não foram vividos durante toda a vivência com o grupo de brincantes e apaixonados pela brincadeira! Ou na ida para a comunidade, ou no seu retorno, ou ao dormir, ou sobre o caderno de anotações, ou enquanto observávamos a movimentação dos brincantes e de seu público atento, conversávamos conosco mesmos sobre as linhas de significação que ia urdindo. $\mathrm{O}$ mp3 foi um importante "mediador" dessa conversa solitária.

Outras dificuldades também são apontadas por Haguette e que tivemos oportunidade de observar em campo: possíveis ambiguidades nas questões apresentadas, falta de confiança do entrevistado em relação ao pesquisador, riscos de uma relação autoritária marcada pela condução feita pelo entrevistador além do fato da relação ser pontuada pela presença de um pesquisador universitário tomado geralmente como uma figura "sofisticada" e de "alta educação" (HAGUETTE, 2010, p. 85). Ao andar pela comunidade Cipó de Baixo, nossa figura logo se destacava como pessoa estranha e "importante" por se tratar de um professor universitário. Essa identificação foi, durante toda a pesquisa, uma dificuldade que procuramos superar pelo envolvimento com as pessoas e por apresentar-nos não somente como um homem que apreciava a brincadeira do reisado.

Desse modo, a entrevista, como técnica de investigação, foi tomada como instrumento complementar de apreensão de informações. Ao tempo que obtínhamos confiança e transformávamos nossa presença em algo habitual, a entrevista serviu para orientar e direcionar nossos interesses de compreender. Ela propiciou um diálogo mais dirigido a pontos que exigiam uma gama maior de informações. As questões propostas lançaram luzes sobre dúvidas registradas no caderno de notas ou nos solilóquios gravados no mp3 e na memória do pesquisador-observador. Nos movimentos inconstantes e atormentados por incertezas, tomamos as entrevistas como mais um meio de compreensão.

Não podemos olvidar que as entrevistas são situações artificiais ou estranhas ao cotidiano daqueles sujeitos. Como tais, eram sempre evitadas. Acabávamos transformando em conversas informais, dirigidas a alguns temas particulares. Esses momentos diferentes, serviam também aos entrevistados como oportunidades para refletir sobre si próprios. 
O ineditismo daquelas situações, provocado pela presença desconhecida de um pesquisador externo com questionamentos "surpreendentes" sobre algo que já é de conhecimento de todos, sugeria a todos uma recapitulação de seus velhos discursos e significados consagrados. Num mundo de linguagem, as entrevistas se deram como metadiscursos acerca de existências de sujeitos determinados culturalmente e interpelados por tantos outros discursos frutos de novas políticas públicas, da indústria cultural, de movimentos sociais, do êxodo rural etc. Nesse sentido, as entrevistas abrem janelas para outros cipós sociais aos quais pertence o reisado. Além de uma brincadeira e um auto popular, o reisado faz parte da trama de relações de parentesco, de um conjunto de tradições das comunidades, comporta relações de gênero e status social, oportuniza processos de socialização, atualiza redes de trocas sociais etc. Na comunidade Cipó de Baixo, constatamos que a técnica da entrevista, associada com a observação participante, pode estender sua margem de apreensão da realidade conforme se desenvolveram as interações entre pesquisador e atores sociais.

Nessa trama de discursos estimulada pela iniciativa do pesquisador, os "entrevistados" transformam-se em sujeitos que refletem sobre suas experiências sociais. Como sujeitos reflexivos, elaboram suas próprias teorias (metadiscursos) acerca do mundo do qual fazem parte. Se não são iguais, mas, de algum modo os metadiscursos reflexivos do pesquisador acadêmico se assemelham àqueles dos atores sociais "pesquisados". Ambos são elaborados com base naquele diálogo artificial proposto pela entrevista. E, certamente, ambos não se findam naquele momento dialógico. Se o pesquisador retoma aquela entrevista inúmeras vezes para elaborar uma síntese explicativa, os atores sociais entrevistados certamente vão se questionar novamente sobre alguns aspectos da conversação que mais lhe chamaram a atenção ${ }^{6}$. Se pode haver diferenciações de sistematização e de rigor reflexivo, em ambos os metadiscursos há uma estratégia reflexiva que se lança além do discurso imediato.

\footnotetext{
${ }^{6}$ O filho de seu Raimundo Milú, Francisco, repetidas vezes dialogara comigo
} retomando antigas ideias ou fatos já tratados em conversações anteriores.
O "pesquisador acadêmico" necessita dessa elaboração metadiscursiva dos atores sociais entrevistados para propor as suas. Se o metadiscurso "científico" incorpora outros referenciais discursivos (conceitos e teorias), jamais prescinde daquele exercício dialógico vivido durante a entrevista. É com o apoio dele que se enreda toda uma trama explicativa. Nós, como outro pesquisador, reescrevemos aqueles "metadiscursos" por meio dos referenciais de pensamento que desenvolvemos principalmente num outro mundo - o acadêmico. Como uma reescrita, só existe, pois, se pessoas alheias ao universo científico se prontificaram em ler suas vidas a partir de algumas provocações sugeridas pelo "cientista". É essa leitura de suas vidas que acaba sendo uma parte considerável da materialidade de nossa pesquisa. E a veracidade dessas leituras? Não nos orientamos sob a ótica de verificar a "verdade" de seus depoimentos. Procuramos seguir a mesma orientação de Ecléa Bosi:

A veracidade do narrador não nos preocupou: com certeza seus erros e lapsos são menos graves em suas consequências que as omissões da história oficial. Nosso interesse está no que foi lembrado, no que foi escolhido para perpetuar-se na história de sua vida. (1994, p. 37).

Almejamos apreender a maneira singular que os atores sociais entrevistados tomaram para explicar suas vidas como brincantes e moradores de uma comunidade rural do município de Pedro II. Suas falas dizem-nos quem eles são e como se veem no mundo por meio da brincadeira do reisado. Compreender esse campo de significados que representa as suas vidas e o que eles esperam de si, dos companheiros e de todos os demais é o que nos interessou.

E como se davam esses exercícios metadiscursivos? Ocorriam em dias em que verificávamos maior tempo e vontade de falar dos entrevistados sobre o reisado e outros tantos cipós participantes da trama dessa tradição. Os diálogos propostos não podiam ser invasivos ou uma espécie de obrigação dos informantes frente ao pesquisador (mesmo porque a nossa presença em seu meio nunca ficou tão clara à exceção do dono do reisado e de seus dois filhos, Francisco e Conceição). Por essa razão, as conversas informais e as entrevistas deviam acontecer com o máximo de naturalidade e conforme a disponibilidade 
e vontade de nossos interlocutores. Somente quando conseguíamos reunir essas condições, estendíamos o nosso campo de visão do reisado e das vidas daqueles atores sociais e suas comunidades. Por essa razão, a proposição dos momentos de entrevistas era objeto quase que exclusivo de nossa subjetividade e bom senso ${ }^{7}$. Ao comentar a concepção de Severyn T. Bruyn sobre a observação participante, Teresa Maria Haguette pondera:

A seu ver, o requisito cardeal de uma ciência empírica é o respeito pela natureza do objeto pesquisado. Ao invés de aplicar à vida humana esquemas importados dos procedimentos científicos, ele enfatiza a necessidade de se reconhecer em primeira instância o caráter peculiar dos seres humanos, seu comportamento e sua vida em grupo. (2010, p. 65).

Por mais que alimentássemos uma urgência interior em obter esclarecimentos sobre as questões da pesquisa, precisávamos exercitar a paciência e o respeito frente à vida daquelas outras pessoas que também possuíam suas urgências e suas necessidades de esclarecimento. Não é porque não fazem parte da tribo acadêmica que não têm suas dúvidas e necessidades de aprender e dialogar. Nossa presença era sempre motivo para iniciar conversações também sobre seus interesses e questionamentos sobre o mundo. Afinal, apresentamo-nos como professor universitário e como um homem que estava ali para ouvir e dialogar. Logo, éramos também um bom informante para eles. Por essa razão, sentíamo-nos, às vezes, como um enciclopedista que era consultado sobre temas os mais diversos.

Para um sujeito com temperamento tímido e de poucas relações, vimo-nos levados a exercitar novas atitudes e posturas frente aos outros. Nesse exercício, fomos aprimorando a arte do diálogo e do reconhecimento de si e do outro. A pesquisa qualitativa em Ciências Humanas pressupõe um envolvimento integral daquele sujeito que se propõe a conhecer melhor os outros sociais que coabitam o mundo. No desenrolar da pesquisa, não são postos em movimento tão somente projeções, métodos, planejamentos e

\footnotetext{
${ }^{7}$ O historiador Alessandro Portelli destaca que "o caminho do pesquisador se cruza com o caminho do narrador em momentos imprevisíveis, e a história de vida coletada é o resultado dessas eventualidades. É claro que o pesquisador pode ter planejado o encontro, mas o entrevistado não. Normalmente, não há motivo inerente na vida dos narradores para que pesquisadores batam à sua porta em algum momento específico" (2005, p. 298).
}

competências intelectuais: a figura do pesquisador é abduzida pelo envolvimento com o universo da pesquisa. Podemos afirmar que emergimos uma pessoa bem diferente daquela que se lançou ao oceano da pesquisa. Certamente que experimentamos algo que consideramos imprescindível para a realização de uma pesquisa qualitativa: uma abertura para descentrar-se. Talvez nós mesmos ainda não possuamos a disponibilidade necessária, apesar do exercício vivido. Em muitos momentos, percebíamo-nos solicitados pelos atores da pesquisa, no entanto, sabíamos que não conseguíamos corresponder às expectativas depositadas". "Quando o outro se transforma em uma convivência, a relação obriga a que o pesquisador participe de sua vida, de sua cultura. Quando o outro me transforma em um compromisso, a relação obriga a que o pesquisador participe de sua história..." (BRANDÃO, 1999, p. 12).

A motivação para o estreitamento dessa relação não adveio somente da pesquisa. Ela foi estimulada também por uma identificação da nossa pessoa com valores e ações humanistas que vimos amadurecendo em nossa jornada como intelectual e cidadão. Compreensão humanista que nos fez desenvolver nesses últimos anos o projeto extensionista "Humanismo Caboclo". Se, de início, o projeto "Humanismo Caboclo" nasceu mais de nosso interesse em contribuir com a formação cidadã de crianças e jovens da zona rural de Pedro II e municípios vizinhos atendidos pela EFA Santa Ângela e Rede de Educação Cidadã (Recid), aos poucos, percebemos que ele se transformou numa grande porta de interação com o universo de nossa pesquisa. Dialogando com os jovens, orientando pesquisas, discutindo sobre os desafios da educação popular, realizando algumas visitas ocasionais as suas famílias e comunidades, fomos estreitando nossa relação com a zona rural de Pedro II e aprendendo mais sobre aquelas pessoas.

\footnotetext{
${ }^{8}$ Ao realizar a última revisão da tese, chegamos à conclusão de que aqueles homens e mulheres foram muito mais desprendidos e generosos que eu. Os participantes da pesquisa, sem sombra de dúvida, foram capazes de disponibilizar-se a maiores e mais profundas trocas que o pesquisador. Devemos muito a todos eles por nos mostrarem o quão mais generosos e comprometidos podemos ser.

${ }^{9}$ Atividade em parceria com a Fundação Santa Ângela e Recid que busca, por meio de ações educativas, refletir sobre a vida de jovens e crianças oriundos da zona rural e sobre suas comunidades. As ações educativas procuram promover uma visão mais abrangente do jovem e criança que mora na zona rural (economia, educação, política, cultura, etc.) e algumas práticas de cidadania emancipatória a partir do diálogo com referenciais da Educação Popular e Sociologia Cabocla.
} 
Como um tópico que descreve as escolhas metodológicas da pesquisa, não podemos omitir a importância do desenvolvimento do Humanismo Caboclo na aproximação e reconhecimento do universo de investigação. Se, a princípio, não classificamos essa experiência extensionista dentro de uma determinada técnica de investigação da realidade, reconhecemos que ela contribuiu muito na construção das considerações que levantamos em todo o transcorrer desse trabalho.

Além dessa vivência no município de Pedro II, motivada por um projeto extensionista com a qual ainda nos ocupamos, nossos diálogos com os filhos do dono do reisado (Francisco e Conceição) estimularam-nos a pensar sobre alternativas de sobrevivência do reisado. Em muitos momentos, largamos o oficio de pesquisador objetivo para, como uma espécie de educador popular, provocar reflexões sobre os sentidos daquela brincadeira tradicional, dos compromissos daqueles jovens em mantê-la e sobre possíveis estratégias de resistência cultural. Como bem descreve Uwe Flick:

[...] os pesquisadores qualitativos não agem com neutralidade invisível, e sim tomam parte quando observam (na observação participante) ou fazem com que os participantes reflitam sobre sua vida e história de vida (em uma entrevista biográfica), o que pode levar os entrevistadores a compreender coisas novas sobre sua situação e o mundo ao seu redor. $(2009$, p. 22).

Ao tempo que o pesquisador realiza seu estudo, está ocorrendo outro exercício de pensamento: aqueles que são entrevistados também vivem uma espécie de autoinvestigação. Se não há esse interesse autoinvestigativo premeditado, de outra maneira, há uma prática de reflexão espontânea e assistemática. A intervenção do pesquisador provoca dizeres, questiona antigas e novas práticas, quebra a monotonia dos conceitos habituados e costumeiros.

De outro modo, suas respostas se transmutam numa prática de narrativa oral de sua história. As pessoas envolvidas, direta ou indiretamente, na brincadeira do reisado experimentam algo inédito em suas vidas que é a contação de sua história durante a realização da pesquisa para um sujeito estranho às suas vidas e proveniente de uma universidade. Todos acabam revisitando discursos antigos e experimentando novos dizeres por meio das especulações propostas pela pesquisa. Como pondera o historiador Alessandro Portelli, contar sua história ou momentos dela para pessoas conhecidas tem suas diferenças em relação às narrativas feitas a um pesquisador:

Frequentemente, o hábito de falar para um público conhecido induz os narradores a mencionar episódios longos e/ou importantes só de passagem, especialmente se já os haviam contado anteriormente; ou referir-se a eles em outras partes da narrativa. Pesquisadores muitas vezes precisam fazer com que o narrador fale mais devagar ou pedir explicações e detalhes, às vezes sobre aspectos ou episódios de interesse para o historiador, mas que pareçam insignificantes para o narrador. (2005, p. 301).

Saber temperar esses diálogos, de modo a satisfazer pesquisador e atores sociais, é um exercício delicado e necessário. Pedir para alguém falar sobre o que é "óbvio" para ele exige cuidados. Procurar retomar fatos ou explicações já dadas ao pesquisador por este reconhecer importantes outros esclarecimentos nem sempre é simples. Por outro lado, à medida que trilhamos esses percursos dialógicos, temos oportunidade de estreitar nossas relações e aprofundar as reflexões de ambos os dialogadores. Não é somente o pesquisador que toma aqueles momentos para ponderar sobre os fatos relatados. Alguns atores sociais, dependendo do assunto e da circunstância, tomam aquelas conversas para rever suas ideias. Uma importante especulação que já havia entre os brincantes diz respeito ao futuro do reisado. Principalmente na figura do filho de seu Raimundo Milú, o Francisco: quando conversávamos com ele informalmente ou realizávamos uma "entrevista", ele aproveitava aquele momento para refletir também sobre as "mudanças" que defende para que o reisado continue existindo. Ao tempo que apresentava suas razões, tinha a oportunidade de externar para si próprio os seus argumentos. Era um momento de ele avaliar melhor suas ideias e, vez por outra, inquirir-nos acerca de nossa opinião. Naquelas oportunidades, dois sujeitos colocavam-se intencionalmente na condição de seres reflexivos.

Não se pode, por outro lado, esquecer também que a presença de um pesquisador na comunidade provoca em seus moradores questionamentos múltiplos sobre o que faz sua comunidade ser objeto de uma pesquisa acadêmica. Desse modo, observamos que a "pesquisa acadêmica" configurou-se como um 
processo de reflexão mútua. Mais do que uma prática investigativa individual, o exercício de investigar é partilhado: não temos um objeto social inerte esperando ser interpretado. Pelo contrário, aqueles sujeitos, que são apropriados como objeto da pesquisa, estão continuamente intervindo na leitura de suas vidas $^{10}$.

As entrevistas esclarecem muito bem a natureza cooperativa da investigação. Ao tempo que os entrevistados dão seus depoimentos, estão ao mesmo tempo refletindo sobre suas vidas. Suas experiências, suas memórias, enfim, toda a extensa gama de suas vidas passa por uma espécie de autoinvestigação. As perguntas do investigador acadêmico acabam por serem suas perguntas; e as ideias (suas respostas) que nascem da provocação das perguntas são nada mais nada menos do que suas teorias sobre o seu mundo. Não estão todos mobilizados para a pesquisa do "sujeito externo": todos se empenham em refletir sobre as questões que lhe interessam e que, de algum modo, lhe perseguem como perguntas recorrentes. Os "atores sociais" não respondem tão somente às questões do sujeito pesquisador (muitas vezes nem respondem). Eles tomam essas perguntas para revisitarem seus questionamentos e suas visões sobre problemas de seu interesse.

A natureza cooperativa da investigação reside no fato de que todos estão, mais ou menos, comprometidos com suas dúvidas e pensamentos. Naqueles momentos de "entrevista", atores sociais e "pesquisador" potencializam suas incertezas e considerações: estão todos catalisando os seus interesses investigativos. Mesmo que as formas de organizá-los sejam bem distintas. Por vezes, desejávamos saber sobre determinado detalhe da brincadeira. Essa janela de diálogo abria outras tantas vias de narrativas ou explicações que, segundo o critério de articulação do pensamento do ator social entrevistado, eram importantes e necessárias. Ou, de modo diferente, ele não reconhecia naquele detalhe algo relevante o que procurava descartar em sua fala.

Mesmo na busca de tecer uma trama de diálogos, há valores e julgamentos distintos em permanente troca. O que é valioso para o pesquisador pode

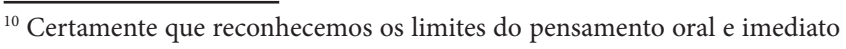
assim como o pensamento escrito e mediato possui os seus. Como pondera Bosi, "faltou-lhes a liberdade de quem escreve diante de uma página em branco e que pode apurar, retocar, refazer" (1994, p. 38).
}

não ser relevante para o ator social dialogador. Essa tecedura de muitas palavras e juízos exige paciência e determinação do pesquisador para questionar seus julgamentos sobre o que é relevante e apreciar pacientemente os dizeres dos atores entrevistados. Portelli orienta que deveríamos “... deixar que nosso discurso seja contaminado - hibridizado, mestiçado e 'miscigenado' - pela característica de romance com que os narradores contam estórias" (PORTELLI, 2005, p. 313) ${ }^{11}$.

Ao procurar entender esse cipoal social que é o reisado, não tomamos uma técnica de observação ou de captação de dados como exclusiva. Pelo contrário, procuramos, à medida que nos deparávamos com os desafios de observação, utilizar-nos dos métodos que pudessem contribuir com a proposta de interpretação do reisado do Cipó. Foi assim que nos apareceu a história de vida. Ainda conforme Haguette (2010, p.75):

Embora o trabalho seja apresentado a partir de seu enfoque (do pesquisador), ele enfatiza o valor da perspectiva do ator por aceitar que a compreensão do comportamento de alguém só é possível quando este comportamento é visto sob o ponto de vista do ator. (parêntese nosso)

Tomar aquelas pessoas "pesquisadas" não somente como "entrevistados", mas como atores sociais que desenvolvem uma trajetória de vida específica e contribuem com seu mundo coletivo de modo bastante singular, é o recorte particular que a história de vida contribui para uma pesquisa nas ciências humanas. Priorizar as experiências e interpretações dos próprios atores estende o jogo de sentidos imerso na trama de cipós do reisado.

Importante observar também que, como essa tradição vem sofrendo transformações ao longo do tempo, decorrentes das mudanças das próprias pessoas e de suas comunidades rurais, a figura do dono do reisado Raimundo Milú é fundamental para sua continuidade. Em muitos sentidos, é a perseverança desse homem e o amor que dedica à brincadeira que têm garantido a resistência do reisado do Cipó. A história de vida contribuiu muito para entendermos melhor esse ator social que tanto fez e faz para a continuidade dessa tradição. Como bem aprecia Haguette, compreender os processos

\footnotetext{
${ }^{11}$ Ver também Dalva Maria de Oliveira Silva, "Algumas experiências no diálogo com memórias" (2005)
} 
tramados na existência social é um desafio nas ciências humanas e a história de vida contribui com esses meandros dos percursos sociais:

Apesar dos sociólogos frequentemente se utilizarem deste conceito, raramente usam os métodos necessários para captar o 'processo em movimento' de que tanto falam. Este 'processo em movimento' é observável, mas não facilmente. Ele requer uma compreensão íntima da vida dos outros, assim como uma técnica, como a história de vida, que nos fornece uma riqueza de detalhes sobre referido processo[...]. (2010, p. 77).

São os detalhes de vida desse ator social que tanto contribuíram para entendermos melhor a história do reisado na comunidade Cipó e circunvizinhas, além do jogo de mediações sociais em que se instala. Sua trajetória de vida, as relações que construiu com as pessoas, as atitudes frente aos brincantes, as posturas tomadas para negociar o reisado com os "capitães", a abertura para apresentar-se em escolas e eventos públicos diversos, suas posições de "homem público" frente às comunidades, todos esses meandros particulares do brincante Raimundo Milú favoreceram uma interpretação mais complexa da tradição do reisado do Cipó e da rede de trocas sociais na qual está inserida.

No mesmo sentido, endossa a historiadora Lucilia Delgado: “... ouvir a história de vida é também partilhar o fazer da História e contribuir para interação entre a experiência pessoal e o fio intrincado da história coletiva" (2006, p. 20). Partilhar e estender a compreensão das múltiplas histórias que se constroem em múltiplos campos de sociabilidade. $\mathrm{Na}$ reflexão da também historiadora Myrian dos Santos (2003), há uma rica indicação de que os estudos contemporâneos sobre memória abrem espaço para compreender os múltiplos discursos que discorrem sobre as experiências sociais de grupos, comunidades ou sociedades. Tratar a história de vida e memórias de seu Raimundo Milú é destacar outra apreensão sobre histórias invisíveis de comunidades, grupos ou tradições. Ao destacarmos a sua vida, desejamos falar sobre vivências temporais e espaciais de grupos e comunidades sempre relegadas ao esquecimento pelos "aparelhos ideológicos de Estado" (ALTHUSSER, 1985). A história de sua vida dá vazão a histórias de tantos outros sujeitos sociais anônimos que animam os sentidos de solidariedade social de inúmeras comunidades rurais piauienses.
Por fim, detemo-nos sobre o emprego de uma filmadora que substituiu, em grande parte, o gravador e o mp3. Depois de nos introduzir no seio da família de seu Raimundo Milú e da própria comunidade, conversar acerca da temática da pesquisa e sentir-nos relativamente à vontade uns com os outros, apresentamos-lhes nossos dois importantes instrumentais de trabalho: câmera fotográfica ${ }^{12}$ e filmadora. Para evitar um constrangimento perante o equipamento ou sua total rejeição, procuramos, inicialmente, tão somente conversar com as pessoas sobre o reisado e suas vidas. Tanto nos foi útil para conhecer melhor aquele mundo novo, como também fomos conquistando a simpatia e o afeto de todos. Esse foi um passo fundamental para aceitação daquele mediador estranho nas nossas conversas. Uns mais, outros menos acabaram por aceitar aquela tecnologia.

E por que o uso da filmagem como recurso instrumental de pesquisa? Inicialmente, percebíamos mais o aproveitamento futuro daquela tecnologia. Sempre imaginamos que teríamos outro padrão discursivo para apresentar os resultados da pesquisa. A formatação de pequenos vídeos, além de sintetizar conclusões, serve também como instrumento educativo. Sonhamos com a montagem de alguns curtas-metragens para ulteriores apresentações em escolas e outras instituições de ensino como material pedagógico. Eles servirão como recursos educativos para discussão de temas tão caros às Ciências Sociais: cultura, diversidade cultural, alteridade, multiculturalismo, cultura popular, política cultural etc. Com a obrigatoriedade da inclusão da Sociologia no ensino médio e a abertura que a LDB dá às escolas para realizarem uma formação cidadã e humanista ampla, aqueles temas não seriam estranhos a esses propósitos (CARNEIRO, 1998). Por outro lado, a crescente incorporação de novas tecnologias ao cotidiano escolar não somente facilita a presença desses documentários como fomenta a sua demanda ${ }^{13}$.

Contudo, à medida que se iniciou a pesquisa, essas justificativas se mostraram menores diante dos ganhos alcançados durante a observação empírica e

\footnotetext{
${ }^{12}$ Infelizmente, as fotos acumuladas durante dois anos de pesquisa foram perdidas quando nosso HD externo queimou. Nele, reuníamos todas as fotos da pesquisa.

${ }^{13}$ Com a defesa da tese imaginamos captar recursos para a produção dos vídeos. Com os recursos de bolsa não nos possível reunir capital suficiente para o nosso intento.
} 
os processos de análise dos dados. São sobre esses ganhos que nos detemos nos próximos parágrafos.

Primeiro, durante as entrevistas, os entrevistados apontam algo, fazem gestos ou mostram algum objeto. Em outras palavras, o sistema comunicativo das entrevistas não se prende ao puro código linguístico. A comunicação se diversifica e complexifica mediante o emprego de uma infinitude de gestualidades. O corpo todo é mobilizado para aquele momento de comunicação. Às vezes, o "sujeito entrevistado" apenas olha para algo e inicia seu depoimento; noutros, um barulho ou uma pessoa que ele avista leva-o a relembrar de um fato ou a novos assuntos O exercício de decupagem das fitas de gravação revelou-nos inúmeras situações de como o corpo atua ativamente na prática da expressão.

De outro modo, o "sujeito entrevistado" fala com variações de entonações e pausas que somente o registro em vídeo é capaz de demonstrar. $\mathrm{O}$ vídeo capta as variações emocionais, os acentos argumentativos, os silêncios que falam, o ambiente à sua volta que interage com a prática discursiva etc. Esses elementos aparecem claramente quando, passados alguns dias (às vezes, meses), o "sujeito pesquisador" procura analisar as entrevistas. À maneira de um déjà-vu, toda aquela gama de expressões é reapresentada na memória do pesquisador.

No exercício solitário de análise, as imagens ainda servem como um estímulo a mais para a disciplina do pesquisador. Todos aqueles elementos imagéticos e sua profusão de significados contribuem com a manutenção da atenção e do interesse de seu intérprete que, após horas ou dias de apreciação, percebe o abatimento crescer paulatinamente. A multiplicidade e riqueza de informações contidas no registro audiovisual são fortes estimulantes para a decupagem interpretativa do pesquisador.

Como bem destaca a historiadora Lucília de Almeida Neves Delgado, a gravação em vídeo contribui em muito com uma forte dificuldade dos processos de entrevista da história oral: "dificuldade de se registrar expressões de rosto e emoções no documento escrito decorrente da entrevista, que não foi gravada em vídeo ou DVD” (2006, p. 20). Esses detalhes subjetivos e de forte expressividade são valiosos para a prática hermenêutica do pesquisador. As imagens gravadas também servem à retroalimentação da memória da pesquisa. Registram aqueles fatos que foram esquecidos pelo "sujeito pesquisador" ao tempo que provocam as insistentes conclusões provisórias. Atuam como um amplo arquivo de acontecimentos que a memória humana jamais seria capaz de memorizar, além de oportunizar novas leituras sobre os fatos pesquisados.

Por outro lado, assim como as entrevistas registradas em alguma tecnologia que capta somente o áudio, as palavras capturadas acabam aprisionadas em alguma mídia que as descontextualiza: os discursos estão privados de sua fluidez espacial e temporal originária e sempre prenhe de sentidos inefáveis. Nossa missão como intérprete da vida social é, ao tempo que atribuímos sentidos novos ao mundo, descartar ou excluir outros tantos significados possíveis. O historiador Alessandro Portelli recorda-nos que, ao transformarmos discurso oral em texto escrito graças à sua gravação anterior, congelamos a plasticidade e vivacidade da narrativa oral:

Enquanto isso assegura a preservação e a recuperação das palavras, também congela sua fluidez. (O italiano, como o espanhol, tem uma palavra apropriadamente metafórica para definir o que acontece com os sons numa fita: incidere, grabar - gravar na pedra.) (sic) Não importa o quanto falemos sobre nós mesmos como historiadores que lidam com relatos orais, a própria tecnologia do nosso trabalho é transformar o oral em palavra escrita, congelar material fluido em um momento arbitrário no tempo. Isto talvez não seja nem "bom" nem "ruim"; de qualquer maneira, talvez não haja nada que possamos fazer. Mas, pelo menos, devemos estar conscientes de que é isto o que fazemos. (2005, p. 300)

Ao registrar uma fala, estamos retirando de seu contexto significativo para tomá-la como objeto de análise. Por mais que nos cerquemos de informações sobre aquela realidade da qual participa o sujeito daquele discurso e procuremos ter ciência e "controle" sobre o momento em que foi tomado o depoimento, jamais conseguimos abstrair todas as circunstâncias, relações e rede de significados que fazem aquele depoimento uma totalidade de significados para o sujeito entrevistado. A instrumentalização da gravação em vídeo oferece-nos um ganho, pois registra um número maior de fatos que circunstanciam um depoimento. Contudo, somos conhecedores de que a cadeia discursiva, com suas referências e significados, depende também de uma ampla gama de outros 
saberes, circunstâncias, memórias, práticas e vivências do entrevistado e de seu grupo social.

Complexidade e contradição perpassam a coluna cervical do pesquisador qualitativo. Não é intenção nossa desenvolver respostas para essas questões. Pelo contrário, nossa intenção é situar em que contexto epistemológico se situa a pesquisa sobre a brincadeira do reisado do Cipó. Por uma honestidade de ofício, contextualizamos as ordenadas da pesquisa de campo realizada em torno dos sentidos e transformações sociais do reisado.

Essa comunicação entre técnicas foi uma estratégia desenvolvida no decorrer da pesquisa. Foi com os desafios apresentados, na trajetória da investigação, que fomos incorporando ferramentas que fossem capazes de subsidiar a leitura daquele mundo, à primeira vista, tão próximo de nossa vida como piauiense e filho de um casal provindo da zona rural, e, depois de outras vistas, tão distante e enigmático. Essa mixagem de técnicas serviu-nos como um estratagema de adaptação às muitas dúvidas e questões elaboradas na caminhada investigativa, ou, como afirma Haguette, “[...] o problema sob investigação é que dita o método de investigação" (2010, p. 95).

Talvez os respeitados leitores possam levantar ressalvas sobre essas escolhas metodológicas. O que podemos afirmar é que, por serem esses instrumentos metodológicos ferramentas de investigação, eles foram tomados como tal a serviço dessa proposta de contemplação de um processo cultural caracterizado pela relação entre as permanências e as transformações da tradição do reisado da comunidade rural Cipó de Baixo. Certamente que as escolhas das técnicas interpretativas influenciam a conformação da interpretação científica. Como parte do exercício de análise de processos culturais, temos convicção de que os instrumentos de coleta de dados só contribuíram para a conformação dessa análise que ora apresentamos. História de vida, observação participante, entrevista, todos esses instrumentais de apreensão da realidade dialogam entre si no cadinho investigativo que publico nesse momento: "Apesar de suas especificidades, na maioria das vezes o pesquisador trabalha com vários métodos ao mesmo tempo [...] dependendo dos propósitos que tem em vista" (HAGUETTE, 2010, p. 95).

Em sentido semelhante, a pesquisadora em educação Marli André destaca que "se admitirmos que a teoria vai sendo construída e reconstruída no próprio processo da pesquisa, temos de aceitar que as opções metodológicas também vão sendo explicitadas e redefinidas à medida que a investigação se desenvolve" (2010, p. 46). Nos vários cipós que percorremos, fomos construindo e reconstruindo a trama de nossa pesquisa: se a problemática investigativa manteve-se a mesma, o modo de investigar flexibilizou-se segundo as necessidades da investigação.

\section{Palavras finais}

Não é objetivo deste artigo aprofundar uma reflexão epistemológica detalhada sobre técnicas e processos investigativos de pesquisa. Nessas páginas, procuramos deter-nos sobre as escolhas de métodos e trajetórias de investigação que nos apropriamos durante o trabalho de apreensão empírica do problema de nossa pesquisa. As considerações ora apresentadas podem ser tomadas como um relato das escolhas feitas mediante os métodos de apreensão da realidade das Ciências Humanas. Como relato é uma visão particular de um pesquisador frente aos caminhos trilhados para apreender o seu objeto de investigação, mas que procura elucidar como se deram as escolhas, por quais razões e com que intenções, independentemente das fronteiras disciplinares.

Nesse sentido, queremos ressaltar que a trama da pesquisa foi urdida por meio de diálogos entre as disciplinas científicas. Jamais houve intenção de realizar uma pesquisa "antropológica" sobre o reisado do Cipó. Pelo contrário, a motivação permanente foi compreender o dinamismo cultural vivido pelos atores do reisado da comunidade Cipó. Tendo em vista essa motivação, não nos prendemos a um referencial restrito de uma ciência. Caminhamos pelas fronteiras, trocando com saberes múltiplos na expectativa de contemplar de modo mais amplo a realidade estudada.

Se, à primeira vista, essa postura pôde causar estranhamento ou rejeição, insistimos na convicção de que conhecimento não se faz em espaço firme tampouco com fronteiras fixas. Ao buscar inspiração em estudiosos diversos e de formações múltiplas, tínhamos em mente a problematização de uma realidade que carecia de um olhar flexível e crítico. Foi essa inspiração que pautou a elaboração teórico- 
-metodológica da pesquisa e não uma filiação feita $a$ priori a uma determinada ciência.

\section{Referencias}

ALTHUSSER, L. Aparelhos ideológicos de Estado: nota sobre os aparelhos ideológicos de Estado (AIE). Rio de Janeiro: Edições Graal, 1985.

ANDRADE, U. M. A tessitura do campo e dos outros. In: . Memória e diferença: os Tumbalalá e as redes de trocas no submédio São Francisco. São Paulo: Humanitas, 2008.

ANDRÉ, M. E. D. A. A pesquisa no cotidiano escolar. In: FAZENDA, I. (Org.). Metodologia da pesquisa educacional. São Paulo: Cortez, 2010.

BAUMAN, Z. O sonho da pureza. In: O mal-estar da pós-modernidade. Rio de Janeiro: Jorge Zahar, 1998.

BECK, U. Liberdade ou capitalismo. São Paulo: Editora UNESP, 2003.

BERGER, P. L.; LUCKMANN, T. A construção social da realidade. Petrópolis: Vozes, 1985.

BOSI, E. Memória e sociedade: lembranças de velhos. São Paulo: Companhia das Letras, 1994.

BOURDIEU, P. A economia das trocas simbólicas. São Paulo: Perspectiva, 1987.

BRANDÃO, C. R. (Org.). Repensando a pesquisa participante. São Paulo: Brasiliense, 1999.

BURKE, P. Hibridismo cultural. São Leopoldo: Ed. Unisinos, 2006.

CANCLINI, N. G. A globalização imaginada. São Paulo: Iluminuras, 2007.

CARNEIRO, M. A. LDB fácil: leitura crítico-compreensiva artigo a artigo. Petrópolis: Vozes, 1998.

DELGADO, L. A. N. História oral: memória, tempo, identidades. Belo Horizonte: Autêntica, 2006.

DURKHEIM, E. As formas elementares de vida religiosa. São Paulo: Paulinas, 1989.

FLICK, U. Desenho da pesquisa qualitativa. Porto Alegre: Artmed, 2009.

GEERTZ, C. A interpretação das culturas. Rio de Janeiro: Guanabara/Koogan, 1989.

GILROY, P. O atlântico negro: modernidade e dupla consciência. Rio de Janeiro: Universidade Cândido Mendes, Centro de Estudos Afro-Asiáticos, 2001.

HAGUETTE, T. M. F. Metodologias qualitativas na sociologia. Petrópolis: Vozes, 2010.
HALL, S. A identidade cultural na pós-modernidade. Rio de Janeiro: DP\&A, 2006.

ORTIZ, R. Um outro território: ensaios sobre a mundialização. São Paulo: Ed. Olho d'Água, 2005.

PORTELLI, A. O momento da minha vida: funções do tempo na história oral. In: FENELON, D. R. e outros (Org.). Muitas memórias, outras histórias. São Paulo: Olho d'Água, 2005.

SANTOS, B. S. Por uma concepção multicultural de direitos humanos. In: FELDMAN-BIANCO, B.; CAPINHA, G. (Org.). Identidades: estudos de cultura e poder. São Paulo: Hucitec, 2000.

SANTOS, M. S. Memória coletiva e teoria social. São Paulo: Annablume, 2003.

SILVA, D. M. O. Algumas experiências no diálogo com memórias. In: FENELON, Déa Ribeiro e outros (Org.). Muitas memórias, outras histórias. São Paulo: Olho d’Água, 2005.

TASSINARI, A. M. I. Introdução. In No bom da festa: o processo de construção cultural das famílias Karipuna do Amapá. São Paulo: Editora da Universidade de São Paulo, 2003.

WEBER, Max. A ética protestante e o espírito do capitalismo. São Paulo: Martin Claret, 2002.

\section{Agradecimentos:}

Ao seu Raimundo Milú, sua família, brincantes e à comunidade rural Cipó de Baixo;

À FAPEPI (Fundação de Amparo à Pesquisa do Piauí) pelo financiamento de nossa pesquisa;

Ao professor e orientador Luiz Assunção e ao Programa de Pós-Graduação em Ciências Sociais da UFRN;

À Universidade Estadual do Piauí por garantir as condições institucionais para realização da pesquisa.

Recebido em: 05 de fevereiro de 2013 Aceito em: 27 de maio de 2013. 